\title{
HUBUNGAN KOORDINASI MATA-KAKI DENGAN KETERAMPILAN SEPAKSILA DALAM PERMAINAN SEPAKTAKRAW PADA MAHASISWA PENJASKESREK UNIVERSITAS HALU OLEO
}

\author{
oleh: \\ SUHARTIWI \\ Dosen Jurusan Pendidikan Jasmani, Kesehatan dan Rekreasi, \\ Fakultas Keguruan dan Ilmu Pendidikan Universitas Halu Oleo \\ Email: -
}

\begin{abstract}
ABSTRAK
Peneliti ini bertujuan untuk mengetahui hubungan koordinasi mata-kaki dengan keterampilan sepaksila dalam permainan sepaktakraw pada mahasiswa Penjaskesrek Universitas Halu Oleo. Penelitian ini dilaksanakan di lapangan Sepaktakraw Universitas Halu Oleo dengan sampel 40 orang. Populasi dalam penelitian ini adalah semua mahasiswa Putra Jurusan Penjaskesrek Universitas Halu Oleo yang memprogram mata kuliah T/P Sepaktakraw. Metode yang digunakan adalah survei dengan teknik analisis korelasional untuk memperoleh data koordinasi mata-kaki dengan menggunakan tes passing and stop, sedangkan untuk memperoleh data keterampilan sepaksila dengan menggunakan tes sepaksila dalam lingkaran yang berdiameter $60 \mathrm{~cm}$ selama 1 menit. Analisa data menggunakan rumusan korelasi product momen dari pearson pada taraf signifikasi $=0,05 \%$. penelitian ini dapat disimpulkan bahwa hasil tes dari kedua variabel yaitu koordinasi mata-kaki (X) dan keterampilan sepaksila (Y) diperoleh nilai $r$-hitung $=0,458$. Hasil tersebut dibandingkan dengan $r$-tabel dengan taraf signifikansi $\alpha$ $=0.05 \%$ dengan $\mathrm{Df}=\mathrm{N}-2=38$ yaitu sebesar $=0,312$ dan taraf signifikansi $\alpha=0.01 \%$ sebesar $=0,403$. Dengan demikian diperoleh $r$-hitung $=0.458>$ r-tabel $=0,312$ dan 0,403. sehingga dapat disimpulkan bahwa hubungan koordinasi mata-kaki dengan keterampilan sepaksila memiliki hubungan yang signifikan. Dengan demikian Hipotesis alternatif $\left(\mathrm{H}_{1}\right)$ diterima dan hipotesis nol $\left(\mathrm{H}_{0}\right)$ ditolak..
\end{abstract}

\section{Kata Kunci: Koordinasi Mata-Kaki, Keterampilan Sepaksila}

\section{PENDAHULUAN}

Olahraga sepaktakraw selalu dipertandingkan baik pada tingkat nasional seperti: PON, Kejurnas senior, yunior, antar mahasiswa maupun tingkat internasional seperti: King's cup, SEA Games, Asian Games, POM Asean, Pelajar Asean serta kejuaraan dunia lainnya, namun prestasinya belum sesuai dengan yang diharapkan. Secara umum prestasi pada cabang olahraga sepaktakraw nasional pada saat sekarang ini, hanya bisa meraih medali perunggu dibawah Thailand dan Malaysia. Menurut pengamatan dari para pelatih dan pengurus PB. PSTI, penyebab kekalahan tim sepaktakraw indonesia karena kelemahan dalam bertahan dengan menggunakan keterampilan sepaksila utamanya pada saat menerima bola serangan dari lawan. Sedangkan tim Thailand dan Malaysia mampu bertahan dengan baik sehingga mampu menahan bola dari serangan lawan. 
Sepaksila pada permainan sepaktakraw merupakan salah satu bagian penting yang harus diperhatikan oleh para pelatih dalam memberikan latihan karena sepaksila adalah induk dalam permainan sepaktakraw, digunakan dari awal hingga akhir permainan serta berperan penting dalam proses penyerangan maupun pertahanan dalam permainan sepaktakraw.

Untuk meningkatkan keterampilan sepaksila pada permainan sepaktakraw dibutuhkan beberapa komponen fisik seperti, kelentukan, keseimbangan, kekuatan otot tungkai, koordinasi, dan akurasi dengan harapan agar atlet sepaktakraw mampu memperlihatkan hasil yang baik di setiap pertandingan dan pelatih mampu memberi perlakuan terhadap atlitnya serta memahami bahwa bukan hanya sekedar serangan yang harus dilatih dan dikembangkan, tetapi pertahanan dengan sepaksila juga harus diperhatikan karena sepaksila adalah keterampilan yang paling banyak dilakukan dalam permainan sepaktakraw.

Sesuai dengan uraian di atas, tentang komponen kondisi fisik yang terkait dalam meningkatkan keterampilan sepaksila pada permainan sepaktakraw, di pilih ssatu komponen yang telah diteliti yaitu koordinasi mata-kaki sebagai upaya terobosan untuk meningkatkan keterampilan sepaksila pada permainan sepaktakraw.

Koordinasi mata-kaki merupakan salah satu unsur yang paling penting dalam melakukan sepaksila, dimana dalam pelaksanaannya melibatkan penglihatan dengan gerakan kaki karena mata mengikuti arah bola bergerak dari bawah ke atas sehingga membutuhkan koordinasi mata dengan kaki yang baik. Terlebih saat menerima bola dari lapangan lawan, harus bisa menahan bola secara tepat pada kaki.

Dari berbagai masalah yang di uraikan di atas, penulis telah mengadakan penelitian tentang hubungan komponen fisik dengan keterampilan sepaksila yang berjudul "Hubungan koordinasi mata-kaki dengan keterampilan sepaksila dalam permainan sepaktakraw pada mahasiswa Penjaskesrek Universitas Halu Oleo".

\section{Keterampilan Sepaksila pada Permainan Sepaktakraw}

Permainan sepaktakraw merupakan suatu permainan masyarakat yang dulunya dikenal dengan nama sepak raga. Permainan sepak raga sangat digemari oleh para pemuda dan masyarakat pada beberapa daerah di Indonesia, terutama yang berdomisili di pesisir pantai seperti : kepualauan Riau, Sumatera Barat dan Makassar.

Sepaktakraw adalah suatu permainan yang menggabungkan kemampuan individual dan kemampuan kerjasama antar pemain. Olahraga ini dimainkan oleh dua regu dan dimainkan di lapangan persegi panjang dengan menggunakan bola yang terbuat dari rotan. Setiap regu terdiri dari tiga orang pemain.

Secara terperinci Iyakrus (1992:2) menjelaskan bahwa sepaktakraw adalah suatu permainan yang menggunakan bola (takraw) yang terbuat dari rotan. Dimainkan di atas lapangan yang berukuran 13,42 $\mathrm{m}$ dan lebar 6,1 $\mathrm{m}$. di tengah-tengah dibatasi oleh jarring atau net seperti permainan voli. Permainan terdiri dari dua pihak yang berhadapan, amsing-masing terdiri dari tiga orang. Dalam permainan ini yang digunakan terutama kaki. Bola dimainkan dengan 
memantulkan bola lewat jaring. Tujuan setiap pihak adalah mengembalikan bola sedemikian rupa sehingga dapat jatuh di lapangan pihak lawan atau menyebabkan lawan membuat pelanggaran atau bermain salah.

Untuk bermain sepaktakraw yang baik, seseorang dituntut untuk mempunyai keterampilan yang baik, keterampilan yang baik adalah pemain harus memiliki kemampuan teknik dasar bermain sepaktakraw.

Kemampuan teknik dasar bermain sepaktakraw terdiri dari beberapa teknik, seperti yang dikemukakan Wafi (1990:30) bahwa secara umum ada dua kemahiran yang asas (keterampilan dasar) dalam sepaktakraw yaitu menyepak dan menanduk. Daripada dua kemahiran ini dipecahkan kepada beberapa kemahiran lain seperti menyepak dengan mengawal, mengumpan dan menerima, membuat servis dan membuat rejaman atau libasan (bahasa Malaysia).

Mengenai teknik-teknik dasar permainan sepaktakraw Darwis (1992:16) mengemukakan bahwa teknik dasar permainan sepaktakraw yaitu :

1. Sepakan (sepaksila, sepak kuda (kura), sepak cungkil, menapak, sepak badek (sepak simpuh).

2. Main kepala (dahi, samping kanan kepala, samping kiri kepala, dan bahagian belakang kepala).

3. Mendada.

4. Memaha.

5. Membahu.

6. Servis.

7. Smash.

8. Blocking (menahan).

Sepaksila digunakan untuk menerima dan menguasai bola, mengumpan dan antaran bola serta menyelamatkan dari serangan lawan. Sepak kuda (sepak kura) digunakan untuk memainkan bola yang datangnya rendah dan kencang atau keras serta menyelamatkan dan mempertahankan dari serangan lawan. Sepak cungkil digunakan untuk mengambil dan menyelamatkan bola bila jauh dan rendah. Menapak digunakan untuk smash ke pihak lawan, menahan/memblok smash pihak lawan serta menyelamatkan atau mengambil bola dekat/diatas net (jaring). Sepak badek (sepak simpuh) digunakan untuk menyelamatkan bola dari serangan lawan mengontrol atau menguasai bola dalam usaha penyelamatan.

Main kepala dengan dahi digunakan untuk memberi umpanan kepada teman, samping kanan dan samping kiri kepala digunakan untuk meyerang pihak lawan serta bagin belakang kepala juga digunakan untuk menyerang pihak lawan dengan tipuan. Mendada digunakan untuk mengontrol bola untuk dimainkan selanjutnya bagi diri sendiri kerena pantulan bola lebih dekat dari badan kita sendiri. Memaha digunakan untuk bertahan dan menyelamatkan bola. Membahu digunakan untuk mempertahankan dari pihak lawan yang mendadak (tiba-tiba), dimana pihak bertahan dalam keadaan terdesak dan dalam posisi yang kurang baik. Servis digunakan sebagai awal permainan, smash digunakan untuk menyerang pihak lawan seta blok adalah menahan bola kembali ke lapangan sendiri.

Teknik dasar dimiliki dengan baik apabila berlatih dengan baik dan bertahap. Namun tidak berarti prestasi sepaktakraw itu hanya ditentukan oleh pemilik teknik dasar yang baik saja, faktor-faktor lain juga ikut menunjang peningkatan prestasi. Seperti yang 
dijelaskan oleh Yusuf dkk (2004:19) bahwa cabang olahraga sepaktakraw yang dikembangkan menjadi sebuah cabang olahraga kompetitif memerlukan beberapa persyaratan yaitu :

1. Dari aspek keterampilan gerak, cabang ini bertumpu pada keterampilan manipulatif.

2. Dari aspek kondisi fisik, khususnya kebugaran yang berakaitan dengan prestasi Karena membutuhkan koordinasi yang baik.

3. Dari aspek keterampilan taktis karena olahraga ini memerlukan kecepatan membuat keputusan. Setiap tindakan harus sempurna dan bahkan pelaksanaannya bersifat otomatis.

4. Stabilitas emosi sangat dibutuhkan karena olahraga ini memerlukan ketenangan dan konsentrasi dalam keadaan koordinasi.

Dari uraian di atas dapat diketahui bahwa teknik dasar dimiliki dengan baik apabila berlatih dengan baik dan bertahap. Namun tidak berarti prestasi sepaktakraw itu hanya ditentukan oleh pemilik teknik dasar yang baik saja, faktor-faktor lain juga menunjang peningkatan prestasi seperti kondisi fisik, keterampilan taktis, dan stabilitas emosi.

Dalam permainan sepaktakraw cukup banyak teknik dasar yang harus dikuasai pemain agar dapat memainkan permainan tersebut dengan baik. Sesuai dengan nama permainan, jelas bahwa lebih banyak gerakan yang dilakukan adalah gerakan sepakan. Gerakan ini sangat penting, dapat dikatakan sebagai ibu dari permainan sepaktakraw karena bola dimainkan terbanyak disepak dengan bahagian kaki, mulai dari permulaan permainan sampai membuat point atau angka dapat dikatakan dengan sepakan. Gerakan sepakan ini di samping untuk melakukan sepak mula (servis), juga untuk menerima servis dan mengumpan.

Darwis

mengemukakan: Sepaksila adalah menyepak bola dengan menggunakan kaki bahagian dalam. Sepaksila dilakukan untuk: 1) Menerima dan meminang (menguasai) bola, 2) Mengumpan dan antaran bola, 3) Menyelamatkan serangan lawan.

Senada dengan pendapat di atas Iyakrus (2009:27) juga mendefinisikan sepaksila sebagai berikut : Sepaksila adalah menyepak bola dengan menggunakan kaki bagian dalam. Sepaksila digunakan untuk menerima dan menguasai bola, mengumpan antar bola dan menyelamatkan serangan lawan.

Dalam melengkapi beberapa pendapat di atas tentang sepaksila, Yusuf dkk (2004:30) yang mengatakan bahwa sepaksila yaitu :

1. Berdiri pada ke dua kaki menghadap ke arah datangnya bola.

2. Berdiri pada satu kaki, pada kiri atau kanan.

3. Bila berdiri pada kaki kiri, maka kaki kanan di tarik ke atas dan telapak kakinya menghadap ke lutut kaki kiri kemudian diturunkan setinggi mata kaki, kaki kiri ditarik lagi ke atas sampai setinggi lutut berulang-ulang.

4. Pemain berdiri pada dua kaki, kaki kiri di depan kaki kanan, berat badan bertumpu pada kaki kiri, menghadap pelambung bola.

5. Bola dilambung diikuti dengan pandangan mata, sehingga pemain mengetahui arah bola dan memprediksi kecepatan bola dan jatuhnya bola. 
6. Kedatangan bola disambut oleh kaki dengan posisi kaki sepaksila. Bola menyentuh kaki di bawa mata kaki, kaki kanan. Bola diarahkan kembali kepada pelambung.

7. Jarak pelambung dan penerima lambungan di muulai $2 \mathrm{~m}$ setelah melambungnya terarah dan tepat ke si pelambung di tempat dia berdiri maka jaraknya diperjauh.

8. Arah bola dapat berubah-ubah. Misalnya ke kiri atau ke kanan pelambung, ke atas kepala dan ke atas jauh ke belakang si pelambung. Bila hal ini dapat dilakukan maka pemain ini dapat dinilai sudah menguasai teknik sepaksila.

Dari pendapat tersebut dapat disimpulkan bahwa teknik sepaksila adalah teknik yang banyak digunakan oleh pemain dengan menggunakan kaki bagian dalam, dimana salah satu kaki dilipat ke atas dengan telapak kaki menghadap ke lutut yang menjadi tumpuan guna menerima, mengumpan dan menyelamatkan serangan lawan dengan bola dapat melambung dengan tinggi dari kepala pemain yang harus dikuasai.

Untuk dapat melakukan sepaksila diperlukan latihan dan pengetahuan tentang cara melakukan teknik sepaksila yang baik. Seperti yang kemukakan oleh Yusuf dkk (2004:31) bahwa teknik dasar sepaksila yaitu:

1. Pemain berada pada kaki kiri dan kanan memantul-mantulkan bola dengan kaki kanan bola menyentuh bagian bawah mata kaki, kaki kanan. Pandangan difokuskan kepada bola.

2. Pemantulan bola dipertinggi dengan cara sepakan diperkuat.

3. Bila gerak kaki kiri yang digunakan untuk merupakan tubuh tetap berdiri relatif diam di tempat maka ini menujukkan anda sudah mahir melakukan sepaksila.

4. Sebaliknya bila kaki kiri itu bergeser ke kiri dan ke kanan dan ke belakang sehingga bergerak dalam lingkaran yang garis tengahnya lebih dari 1 (satu) meter, ini menunjukkan bawa sepaksila anda belum stabil dan belum mantap.

5. Apalagi kalau sudah dapat melakukan sepaksila dengan pantulan pendek sampai berhenti dan memantul-mantulkan lagi, maka sepaksila anda sudah cukup mantap.

Wafi (1991:62) mengemukakan bahwa dalam permainan sepaktakraw tindakan atau strategi menyerang dan bertahan saling bergantian. Jika satu regu membuat serangan, regu yang satu lagi akan bertahan dan jika pertahanannya baik maka dia mampu mengatur serangan, begitulah seterusnya. Ini artinya jika bola dari serangan lawan dapat di ambil oleh lawan maka regu tersebut secara otomatis akan bertindak sebagai pertahanan. Bagaimanapun mahirnya seorang tekong menyerang ke daerah lawan jika pertahanan lawan juga baik serta mengumpan dengan baik maka kemungkinan lawan akan menyerang balik. jika mereka tidak memiliki keterampilan bertahan yang baik tidak akan bisa mencapai kemenangan.

Pada saat bertanding, penyerangan kita bisa saja mematikan, tetapi jika lawan dapat menahan dan mengangkat bola kembali serta menyerang balik ke lapangan kita maka poin akan didapatkan oleh regu lawan jika kita tidak memiliki pertahanan yang baik. Penyerangan memang merupakan hal yang penting dalam permainan sepaktakraw, tetapi tak bisa dipungkiri 
bahwa pertahanan pun harus di maksimalkan. Pertahanan yang paling sering digunakan oleh pemain sepaktakraw adalah bertahan menggunakan sepaksila.

Oleh sebab itu teknik ini perlu dikuasai oleh para pemain guna meningkatkan teknik sepaksila, sehingga baik dalam menerima servis, maupun dalam mengumpan dapat dilakukannya dengan gerakan cepat dan tepat ke arah sasaran. Bagi pemain tingkat pemula penguasaan teknik sepaksila, akan dapat menunjang pelaksanaan teknik lainnya dengan baik pada tingkat lanjutan. Menguasai teknik sepaksila harus dengan teknik perkenaan yang tepat. Dalam hal ini meliputi posisi badan, gerakan tungkai, bidang perkenaan dan arah bola.

\section{Koordinasi Mata-Kaki}

Peningkatan keterampilan sepaksila pada permainan sepaktakraw banyak dipengaruhi oleh kemampuan fisik, maupun kemampuan teknik yang merupakan suatu dasar yang harus dimiliki oleh setiap atlet. Salah satu kemampuan fisik yang harus dimiliki untuk meningkatkan keterampilan sepaksila yaitu koordinasi. Menurut Sharkley (2011:169), koordinasi mengimplikasikan hubungan yang harmonis, penyatuan aliran gerakan yang halus dalam melakukan pekerjaan. Pendapat lain dari Bompa mengatakan bahwa koordinasi adalah kemampuan gerak dasar kompleks, pendekatan yang berhubungan dengan kecepatan, kekuatan, daya tahan dan kelentukan, ini adalah faktor penting yang mendapatkan teknik sempurna dan taktis.

Pendapat Bompa dalam (Ramli, 2011:56) memperjelas bahwa dalam aktivitas olahraga, hampir tidak mungkin seseorang melakukan aktivitasnya hanya dilakukan oleh satu elemen saja, seperti pada keterampilan sepaksila pada permainan sepaktakraw yang terdiri dari rangkaian gerak seperti yang dikemukakan oleh Khalim dkk (1996:19), yaitu : sebelum sentuhan, perlakuan awal, sentuhan dan setelah sentuhan. Rangkaian gerak ini harus memiliki koordinasi mata dan kaki dengan baik untuk mendapatkan perkenaan bola pada kaki secara tepat agar hasil sepakan atau arah bola dapat di arahkan dengan baik.

Koordinasi atau keterampilan dicapai dengan latihan. Pengulangan keterampilan menurunkan hambatan synaptik dalam sistem saraf, yang menaikkan kemungkinan dan akurasi gerakan secara otomatis. Sade (jurnal, 2012:3) mengatakan bahwa seorang pemain sepaktakraw dengan koordinasi yang baik bukan hanya mampu melakukan suatu keterampilan secara sempurna akan tetapi juga mudah dan cepat dapat melakukan keterampilan yang masih baru baginya, mengubah dan berpindah secara tepat dari gerakan yang satu ke pola gerak yang lain

Dari beberapa pendapat yang dikemukakan di atas dapat disimpulkan bahwa koordinasi merupakan kemampuan untuk menggunakan panca indera seperti penglihatan dan pendengaran bersama dengan bagianbagian tubuh tertentu di dalam melakukan kegiatan motorik agar harmonis dengan ketepatan tinggi.

Dalam keterampilan sepaksila diperlukan koordinasi mata kaki agar ketepatan dalam perkenaan bola dan kaki dapat dilakukan dengan baik. Suteja (2009: 2) mengatakan bahwa koordinasi mata kaki adalah 
kemampuan pemain dalam mengintegrasikan antara mata (penglihatan) dengan gerakan kaki secara efektif. Nofriadi (2014: 620) mengatakan bahwa koordinasi gerak mata dan kaki merupakan suatu kemampuan yang terjadi pada motorik kasar. Gerakan motorik kasar merupakan suatu gerakan yang melibatkan otot besar/kasar seperti berjalan, melompat. Dalam mengkoordinasikan gerak mata dan kaki dapat digunakan dalam kegiatan sehari-hari seperti berjalan, menaiki tangga dan sebagainya.

Dari pendapat di atas dapat disimpulkan bahwa koordinasi matakaki adalah kemampuan untuk menggunakan mata dan kaki secara bersama, dimana mata untuk menangkap informasi ke otak kemudian memberi perintah kepada otot untuk berkonrtraksi. Kooordinasi mata-kaki juga penting untuk meningkatkan keterampilan gerak seseorang termasuk diantaranya adalah keterampilan sepaksila yang memerlukan hubungan yang harmonis antara gerak kaki dan informasi yang diberikan oleh mata agar perkenaan bola tepat pada posisi yang sebenarnya.

\section{METODE PENELITIAN}

Adapun desain penelitian yang digunakan dalam penelitian ini adalah:

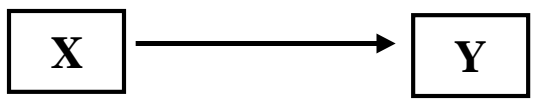

Gambar 1. Desain Penelitian

Sumber : Sugiyono (2016:8)

Metode yang digunakan dalam penelitian ini adalah penelitian survey dengan menggunakan tes dan pengukuran. Adapun varibel yang dilibatkan dalam penelitian ini antara lain : Koordinasi Mata-Kaki adalah variabel X, dan Keterampilan Sepaksila sebagai variabel terikat $\mathrm{Y}$.

\section{Pengumpulan Data}

Pengumpulan data penilitian ini dilakukan dengan menggunakan tes dan pengukuran. Untuk memperoleh data dalam penelitian ini dilakukan tes dengan langkah-langkah sebagai berikut; (1) melakukan survey awal, (2) menyiapkan tenaga lapangan, (3) menyiapkan sampel, dan (4) melakukan tes dan pengukuran dari kedua variabel yang ada.

\section{HASIL DAN PEMBAHASAN}

Pengujian korelasi digunakan untuk mengetahui apakah kedua variabel memiliki hubungan yang signifikan. Pengujian ini menggunakan rumus korelasi product moment yang hasilnya dapat dilihat pada tabel berikut:

Tabel 1. Pengujian Korelasi anatara variabel $\mathrm{X}$ dan $\mathrm{Y}$

\begin{tabular}{|c|c|c|c|c|l|}
\hline \multirow{2}{*}{ Variabel } & \multirow{2}{*}{ Df } & \multirow{2}{*}{$\mathrm{r}_{\text {-hitung }}$} & \multicolumn{2}{|c|}{$\mathrm{r}_{\text {-tabel }}$} & \multirow{2}{*}{ Kesimpulan } \\
\cline { 3 - 4 } & & 0.05 & 0.01 & \\
\hline $\begin{array}{c}\mathrm{X} \text { dengan } \\
\mathrm{Y}\end{array}$ & 38 & 0.458 & 0.312 & 0.403 & Signifikan \\
\hline
\end{tabular}

Dari data di atas bahwa hasil tes dari kedua variabel yaitu koordinasi mata-kaki (X) keterampilan sepaksila (Y) diperoleh nilai r-hitung $=0,458$. Hasil tersebut dibandingkan dengan $r-$ tabel dengan taraf signifikansi $\alpha=0.05$ $\%$ dengan $\mathrm{Df}=\mathrm{N}-2=38$ yaitu sebesar $=0,312$ dan taraf signifikansi $\alpha=0.01$ $\%$ sebesar $=0,403$. Dengan demikian diperoleh $\mathrm{r}$-hitung $=0,458>$ r-tabel $=$ 0,312 dan 0,403 . sehingga dapat disimpulkan bahwa hubungan koordinasi mata-kaki dengan 
keterampilan sepaksila memiliki hubungan yang signifikan. Dengan demikian Hipotesis alternatif $\left(\mathrm{H}_{1}\right)$ diterima dan hipotesis nol $\left(\mathrm{H}_{0}\right)$ ditolak.

\section{KESIMPULAN}

Dari hasil penelitian ini dapat disimpulkan bahwa hasil tes dari kedua variabel yaitu koordinasi mata-kaki (X) keterampilan sepaksila (Y) diperoleh nilai $\mathrm{r}$-hitung $=0,458$. Hasil tersebut dibandingkan dengan r-tabel dengan taraf signifikansi $\alpha=0.05 \%$ dengan Df $=\mathrm{N}-2=38$ yaitu sebesar $=0,312$ dan taraf signifikansi $\alpha=0.01 \%$ sebesar $=$ 0,403 . Dengan demikian diperoleh $\mathrm{r}$ hitung $=0,458>$ r-tabel $=0,312$ dan 0,403 . sehingga dapat disimpulkan bahwa hubungan koordinasi mata-kaki dengan keterampilan sepaksila memiliki hubungan yang signifikan. Dengan demikian Hipotesis alternatif $\left(\mathrm{H}_{1}\right)$ diterima dan hipotesis nol $\left(\mathrm{H}_{0}\right)$ ditolak.

\section{DAFTAR PUSTAKA}

Darwis, Ratinus. 1992. Olahraga Pilihan Sepaktakraw. Jakarta: Depdiknas.

Iyakrus. 2009. Permainan Sepaktakraw. Palembang: Penerbit Unsri.

Khalim, Daud Hj. 1996. Sepaktakraw. Edisi pertama. Malaysia: Tunas Cemerlang.

Mohammad, Ahmad Wafi. 1996. Sepaktakraw. Cetakan ke enam. Malaysia: Fajar Bakti.

Novriadi, Markis dkk. 2014. Meningkatkan Kemampuan
Berjalan Melalui Latihan Menendang Bola bagi Anak Cerebal Palsy Kelas Dasar di SLB Hikmah Miftahul Jannah Padang. Jupekhu. Vol 3 No 1. Ejournal.fip.unp.ac.id.

Sade, Suparman. 2012 Kontribusi Kekuatan Otot Tungkai, Kelentukan dan Koordinasi Mata Kaki terhadap Kemampuan Sepaksila pada Permainan Sepaktakraw Siswa SMP Negeri 13 Makassar. Motion Volume III No. 1 www.journal.unisma.net.

Sharkley, Brian J. 2011. Kebugaran dan Kesehatan. Diterjemahkan oleh Eri Desmarini Nasution. Jakarta: PT. Grafindo Persada.

Sugiono. 2016. Statistika Untuk Penelitian, Bandung: CV, Alfabeta.

Suteja. 2009. Pengaruh Metode Latihan dan Koordinasi Mata Kaki terhadap Keterampilan Bermain Sepaksila. Tesis. Surakarta: Unisma.

Yusuf, Ucup. 2004. Pembelajaran Permainan Sepaktakraw. Jakarta: Depdiknas 